\title{
Family-Type Subsistence Incomes
}

\author{
Christos Koulovatianos, Carsten Schröder, Ulrich Schmidt
}

March 12, Berlin

\section{Extended Abstract}

Do observed aggregate family-consumption expenditures stem solely from preferences that reflect consumer "wants" or is it that, alternatively, these expenditures contain a part that reflects family-type specific "needs?" Plausibly, to set up a certain household type may require a minimum housing rent, maintenance flows of a minimum stock of durables, even subsistence needs, such as minimum calorie and heating needs. Such an aggregate component comprises a fixed consumption flow that is difficult to identify by observing consumer choices. To cover the fixed component of consumption flows may take a large part of the disposable income of poorer households, whereas the remaining income may not be enough to contribute to the purchase of goods that contain significant within-household sharing potential.

The identification of fixed costs of consumption can serve the purpose of estimating family-type subsistence needs, measured in terms of income. Family-type specific subsistence incomes are just adequate to guarantee existence and sustainability of a given family type: they guarantee survival of household members and sustainability of the pertinent household type. In other words, for levels of well-being greater than or equal to the level of well-being at the family-type subsistence income, expenditure functions should be in additively-separable form: they should be the sum of the family-type subsistence income level and a term that depends on the level of wellbeing.

To identify fixed costs of consumption, one needs to uncover the nature of expenditure functions. Yet, as expenditure functions depend on levels of well-being, a way to convert levels of well-being to an observable economic variable is necessary. In our survey, our respondents make this conversion: we ask questions of the form "which net family income level can make a household with two adults and one child as well off as a household with one adult and no children and a net family income of \$1000?" So, we use a single-childless adult household as a reference household. We ask this question for several different incomes of the reference household, i.e. for several reference incomes, that capture several levels of well-being. Responses of our survey participants are "equivalent income" assessments, incomes that make the well-being of households with different family types equal. Equivalent-incomes practically create a stepping stone for the identification of family-type fixed costs (subsistence levels): the so called, "equivalent income functions." This information enables us to distinguish the fixed component of expenditure functions from their variable component.

Our database also allows for testing the nature of the variable component of the equivalent-income functions, so it serves as a guide for building models. Specifically, Donaldson and Pendakur (2005) suggest a formulation for equivalent-income functions with a fixed component and a variable component that is proportional to the reference income: "Generalized Absolute Equivalence Scale Exactness" (GAESE). Our data from six countries, Germany, France, Cyprus, China, India and Botswana, indicate that 
GAESE is the correct specification of equivalent-expenditure functions: A specification test for GAESE is passed for all family types, and in all six countries. The direct estimates of the fixed component of the equivalent income functions are also direct estimates of the fixed component of the expenditure functions for all family types.

Our evidence in favour of the GAESE formulation means that a simple parametric functional form is available and the parameter estimates we provide carry information for several applications. One of these applications is the identification of family-type subsistence incomes: We follow the convention that whenever household-size economies become zero, a household type is not (at least rationally) sustainable. By our convention, the income that corresponds to zero household-size economies is the family-type subsistence income. We report estimates of significantly positive family-type subsistence incomes for all six countries.

Another application is using our estimated parameters to convert the familyincome distributions of a heterogeneous family-type population into income distributions of single equivalent adults. Concerning this application we emphasize that the GAESE formulation and our estimates imply household-size economies that increase with the level of well-being. In other words, according to our estimates, the poor have a lower ability to share their chosen consumption goods. This contrasts sharply the usual hypothesis of "Independence of Base" (IB), as it was coined by Lewbel (1989), or equivalently this of "Equivalence Scale Exactness" (ESE), as it was also named by Blackorby and Donaldson (1991 and 1993) according to which rich and poor have exactly the same ability to share their chosen goods. We use the LIS data on the 2000 German income distribution and we apply our estimates of equivalent incomes. We show that, taking into account the disadvantage of the poor to share goods, the Gini coefficient is significantly higher compared to using our closest adjusted estimates that produce equivalent income functions consistent with IB/ESE.

\section{References}

Blackorby, C., Donaldson, D. (1991): "Adult-equivalence scales, interpersonal comparisons of well-being, and applied welfare economics." In: Elster, J., Roemer, J. (Eds.), Interpersonal Comparisons and Distributive Justice. Cambridge University Press, Cambridge, pp. 164-199.

Blackorby, C., Donaldson, D. (1993): "Adult-equivalence scales and the economic implementation of interpersonal comparisons of well-being." Social Choice and Welfare $10,335-361$.

Donaldson, D., Pendakur, K. (2005): "The Identification of Fixed Costs from Consumer Behaviour," Journal of Business and Economic Statistics 24(3), 255-265.

Lewbel, A. (1989): "Household equivalence scales and welfare comparisons." Journal of Public Economics 39, 377-391. 